\title{
Ameliyathane Hemşirelerinin Eleştirel Düşünme Eğilimlerinin Belirlenmesi
}

\author{
Serdar Sarıtaş ${ }^{1} \oplus$, Maksude Yıldırım²
}

'İnönü Üniversitesi, Cerrahi Hastalıkları Hemşireliği, Malatya, Türkiye

${ }^{2}$ Adıyaman Üniversitesi, Pediatri Hemşireliği, Adıyaman, Türkiye

Serdar Sarıtaş, Dr. Öğr. Üyesi Maksude Yıldırım, Arş Gör.
İletişim:

Dr. Öğr. Üyesi Serdar Sarıtaş İnönü Üniversitesi, Cerrahi Hastalıkları Hemşireliği, Malatya, Türkiye Tel: +905356426332

E-Posta: serdarsaritas44@hotmail.com

Gönderilme Tarihi : 26 Temmuz 2018

Revizyon Tarihi : 10 Ekim 2018

Kabul Tarihi : $\quad 14$ Ekim 2018
ÖZET

Amaç: Turgut Özal Tıp Merkezi (TÖTM) ameliyathanesinde çalışan hemşirelerin eleştirel düşünme eğilimlerinin incelenmesi amacı ile tanımlayıcı olarak yapılmıştır.

Gereç ve yöntem: Çalışmaya Turgut Özal Tıp Merkezi (TÖTM) ameliyathanesinde çalışan raporlu ve izinli olmayan, araştırmaya katılmayı gönüllü olarak kabul eden 58 hemşire katılımıştır. Veriler Kasım 2013 - Ocak 2014 tarihleri arasında toplanmıştır. Veri toplamada 7 sorudan oluşan kişisel bilgi formu ve California Eleştirel Düşünme Eğilim Ölçeği kullanıııışıı. Araştırmada elde edilen verilerin istatistiksel analizi, SPSS16 kullanılarak, sıklık, yüzde, aritmetik ortalama ve standart sapmaların hesaplanması ile değerlendirildi.

Bulgular: Bu araştırmaya katılan hemşirelerin büyük çoğunluğunu \%51.7 18-25 yaş arası hemşire oluşmaktadır. Meslekteki hizmet sürelerine bakıılığında büyük çoğunluğu (\%63.8) 1-5yıl arası oluşturmaktadır. Bunu yanı sıra hemşirelerin \%79.3'ünün eğitim durumunun lisans olduğu, \%91.4'ünün eleştirel düşünme kavramının ne olduğuna dair bilgiye sahip olduğu görülmektedir. Eleştirel düşünme kavramının ne olduğunu hemşirelerin \%30.2'si üniversitedeki derslerden öğrendiklerini, \%45.3'ü ise iş ortamında yaşadıkları olayların eleştirel düşünmelerini etkilediğini söylemiştir. Eleştirel düşünce eğilim ölçeğine göre analitik düşünce puan ortalaması $46.15 \pm 5.53$, açık fikirlilik puan ortalaması $44.13 \pm 9.02$, meraklılık puan ortalaması $41.77 \pm 4.72$, kendine güven puan ortalaması $30.24 \pm 5.18$, doğru analiz yeteneği puan ortalaması $24.74 \pm 4.81$, sistematiklik puan ortalaması $23.82 \pm 2.95$ olarak hesaplanmıştır. California Eleştirel Düşünme Eğilim Ölçeği ortalama puanı ise 210.85 olarak bulunmuştur.

Sonuç: Bu çalışma sonucunda, hemşirelerin çalışma koşullarının olumsuz etkilerinden dolayı eleştirel düşünmelerinin yetersiz olduğu görülmüştür. Hemşirelerin çalışma saatlerinin haftalık 40 saat tutulması, hemşirelerin eleştirel düşünmelerine yönelik eğitimlerin düzenlenmesi halinde eleştirel düşünme eğilimlerinin artacağı tahmin edilmektedir.

Anahtar sözcükler: Ameliyathane hemşiresi, Eleştirel düşünme, Cerrahi

\section{DETERMINATION OF CRITICAL THINKING TRENDS OF OPERATING ROOM NURSES}

\section{ABSTRACT}

Objective: An examination of the critical thinking tendencies of nurses working in Turgut Ozal Medical center's (TOMC) operating room was done descriptively with the aim.

Materials and Methods: 58 nurses working in the Turgut Ozal Medical center's (TOMC) operating room, who are umreported and unauthorized?? And voluntarily accepted to participate in the study, were presented. The data were collected between November 2013 and January 2014. Personal data form consisting of 7 questions and California Critical Thinking Tendency Scale were used in data collection. The statistical analysis of the data obtained in this study was evaluated using SPSS 16, calculating frequency, percentage, arithmetic mean and standard deviations.

Results: The vast majority of the nurses participating in this study were consisted of $51.7 \%$ nurses between the ages of 18-25. Considering the occupational period of service, the vast majority of the nurses $(63.8 \%)$ were between $1-5$ years in service. In addition to this, it was noticed that $79.3 \%$ of nurses had education status and $91.4 \%$ of them had knowledge about the concept of critical thinking). $30.2 \%$ of nurses have learned the concept of critical thinking from their lessons at the university and $45.3 \%$ said that the events they experienced in the business environment affected their critical thinking.

According to the critical thinking trend scale, the mean score of analytical thinking was $46.15 \pm 5.53$, open mindedness score $44.13 \pm 9.02$, curiosity score $41.77 \pm 4.72$, self confidence score $30.24 \pm 5.18$, accuracy analysis ability score $24.74 \pm 4.81$, systematic score average $23.82 \pm 2.95$. The California Critical Thinking Tendency Scale average score was found as 210.85 .

Conclusion: As a result of this study, it was found that critical thinking of nurses was inadequate due to the adverse effects of working conditions. It is anticipated that the tendency of critical thinking of nurses will increase if the nurses' working hours are kept as 40 hours per week, and the nurses are being educated about their critical thinking.

Keywords: Operating room nurse, Critical thinking, Surgery 
D üşünme, içinde bulunulan durumu anlayabilmek için yapılan aktif, amaca yönelik organize edilmiş zihinsel bir süreç olarak tanımlanmaktadır (1). Eleştirel düşünme ise Ulusal Hemşirelik Akreditasyon Komisyonunun (NLNAC) tanımına göre; gerçeklere ve inanışlara dayanan bilginin toplanması, değerlendirilmesi, sunulması, sonuçların oluşturulması, analiz ve müzakere edilmesi süreci olarak tanımlanmaktadır (2). Cüceloğlu (1995) ise eleştirel düşünmeyi, "kendi düşünme süreçlerimizin farkında olarak, başkalarının görüşlerini göz önünde bulundurarak öğrendiklerimizi uygulayarak, kendimizi ve çevremizdeki olayları anlayabilmeyi amaç edinen aktif ve organize zihinsel bir süreç" olarak tanımlamaktadır (3).

Son zamanlarda hızlı teknolojik gelişmeler sağlık bakım alanında değişime neden olmaktadır. Bu değişim, taleplerin ve sağlık çalışanlarının sorumluluklarının artmasına neden olmaktadır (4). Aynı zamanda bu hızlı değişim hemşirelerin kanıta dayalı uygulamalar yapmasını gerektiren karmaşık durum ve problemlerle daha fazla karşılaşmalarına neden olmaktadır (5). Bu nedenle hızı karar vermeyi gerektiren karmaşık hasta bakımı durumlarıyla sık karşılaşan hemşirelerin (6) eleştirel düşünme yeteneğine sahip olmaları hemşirelikte olası problemlerin önüne geçmeyi sağlayacak ve bakımın kalitesini arttıracaktır.

Verilen hizmetin kalitesi, etkinliği ve yeterliliği, meslekteki profesyonellik, otonomi ve güç sahibi olma gibi durumlar hemşirelerin eleştirel düşünme becerileri ile doğru orantılı olarak değişmektedir. Bu nedenle hemşireler ne kadar iyi düzeyde eleştirel düşünme becerisine sahip olurlarsa o ölçüde toplumun sağlığını koruma, geliştirme ve yaşam kalitesini arttırma yönünde etkin hizmet verebilirler (7).

Yapılan her uygulamanın direk insan hayatını etkilediği hemşirelik mesleğinde, eleştirel düşünme son derece önemli bir yere sahiptir. Özellikle ameliyat öncesi, sırası ve sonrasında hasta bakımını kapsayan ameliyathane hemşireliğinde, hemşirelerin kısa sürede doğru kararlar vermeleri hayati önem taşıdığı için eleştirel düşünme ayrı bir önem kazanmaktadır. Çünkü eleştirel düşünen bir hemşire yaptığı her uygulamanın sebep-sonuç ilişkisini sorgulayarak yapılabilecek yanlış uygulamaların önüne geçecektir. Eleştirel düşünme kaliteli hemşirelik hizmetinin sunulmasını sağlayacak ve hemşirelik mesleğinin kalitesini arttıracaktır.

\section{Gereç ve Yöntem}

Bu araştırma Turgut Özal Tıp Merkezi ameliyathanesinde çalışan hemşirelerin eleştirel düşünme eğilimleri ve etkileyen faktörlerin incelenmesi amacıyla tanımlayıcı türde yapılmıştır. Araştırmanın evrenini Turgut Özal Tıp Merkezi Ameliyathanesinde çalışan 65 hemşire oluşturmuştur. Araştırmanın örneklemini ise izinli ve raporlu olmayan, araştırmaya katılmayı gönüllü olarak kabul eden 58 hemşire oluşturmuştur. Araştırmaya başlamadan önce, araştırmanın yapıldığı hastanenin bağlı olduğu Malatya Klinik Araştırmaları Etik Kurulun'dan yazılı izin alınmıştır. Araştırmanın yapılabilmesi için İnönü Üniversitesi Tıp Fakültesi Başhekimlik onayı alınmıştır. Araştırmaya katılacak hemşirelere araştırmanın amacı anlatılarak" aydınlatılmış onam" ilkesine uyulmuştur. Araştırma verileri "gönüllü katılım" ilkesi esas alınarak toplanmıştır. Bireysel bilgilerin araştırmacı ile paylaşıldıktan sonra korunacağı söylenerek "gizlilik ve gizliliğin korunması" ilkesine uyulmasına özen gösterilmiştir.

\section{Veri toplama araçları}

Araştırma verilerinin toplanmasında kişisel bilgi formu ve California Eleştirel Düşünme Eğilim Ölçeği kullanıımıştır.

Kişisel Bilgi Formu: Konu ile ilgili literatürden yararlanılarak araştırmacı tarafından hazırlanmıştır. Bu formda; yaş, öğrenim durumu, medeni durum, meslekte kaç yıldır çalıştığı, eleştirel düşüncenin ne olduğu hakkında bilgisinin olup olmadığı, eleştirel düşüncenin ne olduğunu biliyorsa bilgi kaynağının ne olduğu, eleştirel düşünceye etki eden faktörlerin ne olduğu ile ilgili 7 soru bulunmaktadır.

California Eleştirel Düşünme Eğilimi Ölçeği: Bu ölçek 1990 yılında Amerikan Felsefe Derneğinin düzenlediği "Delphi Projesi"nin bir sonucu olarak Facione tarafından geliştirilmiş ve 2003 yılında Türkçe geçerlilik ve güvenilirlik çalışması Kökdemir tarafından yapılmıştır. Ölçeğin iç tutarlılık katsayısı 0.88 olarak bulunmuş, bu çalışmada ise 0.83 olarak hesaplanmıştır. California Eleştirel Düşünme Eğilim Ölçeği altı maddeli likert tipte bir ölçektir. Maddelerin değerlendirilmesinde: "Hiç katılmıyorum", "katılmıyorum", "kısmen katılmıyorum", "kısmen katılıyorum", "katılıyorum", "tamamen katılıyorum" ifadeleri kullanılmaktadır (sırasıyla; 1,2,3,4,5,6 puan). Ölçekten minimum 51 maksimum 306 puan alınmaktadır. Ölçekten alınan puan arttıkça eleştirel düşünme eğilimleri de artmaktadır. Ölçekteki 05, 06, 09, 11, 15, 18, 19, 20, 21, 22 , $23,25,27,28,33,36,41,43,45,47,49,50$ numaralı maddeler ters çevrilerek puanlanmaktadır.

Ölçeğin; doğruyu arama (madde; 06,11,20,25,27,28,49), açık fikirlilik (madde; 05,07,15,18,22,33,36,41,43,45,47, 50), analitiklik (madde; 02,03,12,13,16,17,24,26,37,40), 
sistematiklik (madde; 04,09,10,19,21,23), kendine güven (madde; $14,29,35,39,44,48,51$ ) ve meraklılık (madde; $01,08,30,31,32,34,38,42,46)$ olmak üzere altı alt ölçeği bulunmaktadır (8).

Toplanan veriler bir istatistik programı olan SPSS paket programına aktarılarak; sıklık, yüzdelik, aritmetik ortalama ve standart sapmalar ile analiz edilmiştir. Sıklık ve yüzdelik ifadeler, hemşirelerin değerlendirilen özelliklerini sayısal olarak verirken, aritmetik ortalamalar, likert tipi ifadelerde genel olarak hemşirelerin nasıl bir eğilim içinde olduğu belirlenmiştir. Standart sapmalar ise genel eğilim etrafındaki negatif ve pozitif uçların dağılımı hakkında bilgi vermektedir. Bu araştırma sadece Turgut Özal Tıp Merkezi Ameliyathanesinde çalışan hemşirelere genellenebilir, başka bir gruba genellenemez.

\section{Bulgular}

Bu bölümde araştırma kapsamına alınan 58 hemşireye ilişkin tanıtıcı özellikler ve hemşirelerin eleştirel düşünme ölçeğinden aldıkları puanlara ilişkin bulgular ve yapılan istatistiksel analizler yer almaktadır.

Tablo 1 de araştırmaya katılan hemşirelerin tanıcı özellikleri yer almaktadır. Hemşirelerin büyük çoğunluğunu \%51.7 18-25 yaş arası hemşire oluşmaktadır. Meslekteki hizmet sürelerine bakıldığında büyük çoğunluğu $\% 63.8$ 1-5yıl arası oluşturmaktadır. Hemşirelerin eğitim durumu incelendiğinde ise büyük çoğunluğu \%79.3 lisans mezunu hemşireler oluşturmaktadır.

Bu çalışmada hemşirelerin \%91.4'ünün eleştirel düşünme kavramının ne olduğuna dair bilgiye sahip olduğu, \%30.2'sinin eleştirel düşünmeyi üniversitede derslerden öğrendikleri ve \%45.3'ünün iş ortamında yaşadıkları olaylardan dolayı eleştirel düşündükleri bulunmuştur (Tablo 2).

Hemşirelerin eleştirel düşünme ölçeğinin alt boyutlarından aldıkları puan ortalamaları incelendiğinde; analitik düşünce $46.15 \pm 5.53$, açık fikirlilik 44.13 \pm 9.02 , meraklılık $41.77 \pm 4.72$, kendine güven $30.24 \pm 5.18$, doğru analiz yeteneği $24.74 \pm 4.81$, sistematiklik $23.82 \pm 2.9531$ puan ve toplam puan ise $210.85 \pm 32.21$ olarak hesaplanmıştır.

\section{Tartışma}

Hemşirelerin, profesyonel hasta bakım yönetiminde problem çözme, karar verme ve eleştirel düşünme gibi süreçleri sık olarak kullanmaları gerekmektedir. Özellikle eleştirel düşünme, hemşirenin bakımla ilgili mantıkı kararlar verebilme, olayları sorgulama ve problem çözme becerisi
Tablo 1. Hemşirelerin tanitıcı özellikleri

\begin{tabular}{|c|c|c|}
\hline Hemşirelerin tanıtıcı özellikleri & Sayı & Yüzde \\
\hline \multicolumn{3}{|l|}{ Yaş } \\
\hline $18-25$ & 30 & 51.7 \\
\hline $26-30$ & 17 & 29.3 \\
\hline $31-35$ & 6 & 10.3 \\
\hline 36 ve üzeri & 5 & 8.7 \\
\hline \multicolumn{3}{|l|}{ Eğitim durumu } \\
\hline Sağlık Meslek Lisesi & 8 & 13.8 \\
\hline Ön lisans & 4 & 6.9 \\
\hline Lisans & 46 & 79.3 \\
\hline \multicolumn{3}{|l|}{ Medeni durum } \\
\hline Evli & 27 & 46.6 \\
\hline Bekar & 31 & 53.4 \\
\hline \multicolumn{3}{|l|}{ Meslek yılı } \\
\hline $1-5$ & 37 & 63.8 \\
\hline $6-10$ & 14 & 24.1 \\
\hline $11-15$ & 4 & 6.9 \\
\hline 16 ve üzeri & 3 & 5.2 \\
\hline \multicolumn{3}{|l|}{ Birimdeki hizmet yılı } \\
\hline $1-5$ & 43 & 74.1 \\
\hline $6-10$ & 10 & 17.2 \\
\hline $11-15$ & 4 & 6.9 \\
\hline 16 ve üzeri & 1 & 1.7 \\
\hline
\end{tabular}

Tablo 2. Hemşirelerde eleştirel düşünme kavramı

Sayı

Yüzde

Eleştirel düşünmeyi bilme durumu

Evet

Hayır

Eleştirel düşünmenin öğrenildiği kaynak

Üniversite

Kitaplar

İş yeri

Diğer (gazete, dergi, kongre vb)

Eleştirel düşünmeye etki eden durumlar

$\begin{array}{lcc}\text { Çevre } & 5 & 9.4 \\ \text { İş ortamı } & 24 & 45.3 \\ \text { Diğer (adaletsizlikler, toplumsal sorunlar vb) } & 24 & 45.3\end{array}$


kazanması bakımından çok önemlidir. Hemşirelerin almış oldukları mesleki eğitim, deneyim ve eleştirel düşünebilme yeteneği, hastaya uygulanan bakım planı sürecini etkiler ve hastanın bakım gereksinimleri en sağlıklı şekilde belirlenmesini sağlar (9).

Hızlı değişimlerin yaşandığı ve karar vermenin yaşamsal olduğu hemşirelik gibi uygulamalı mesleklerde eleştirel düşünme büyük önem taşımaktadır (6). Ameliyathane hemşirelerinin eleştirel düşünme eğilimleri ve etkileyen faktörleri incelemek için yapılan bu çalışmanın bulguları ilgili literatür ile tartışılmıştır.

Gürol Aslan ve arkadaşları (2009) hemşirelerle yaptıkları çalışmalarında eleştirel düşünme puan ortalamasını $200.08 \pm 21.95$, açık fikirlilik puan ortalamasını $40.34 \pm 8.74$, analitiklik puan ortalamasın $51.87 \pm 6.31$, meraklıık puan ortalamasını $33.55 \pm 5.46$, kendine güven puan ortalamasını $27.47 \pm 4.91$, doğruyu arama puan ortalamasını $24.76 \pm 4.92$ ve sistematiklik puan ortalamasını $20.68 \pm 3.84$ olarak hesaplamışlardır (10). Karadağ $\mathrm{M}$ ve arkadaşlarının (2018) hemşirelik ve ebelik öğrencileri ile yaptıkları çalışmalarında öğrencilerin eleştirel düşünme eğilimlerinin alt boyutlarından en yüksek puan ortalamasını analitik alt boyutundan (44.54), en düşük puan ortalamasını ise sistematiklik alt boyutundan aldıklarını (14.98) ve öğrencilerin eleştirel düşünme eğilimi ölçeği toplam puan ortalamalarının ise 214.45 puan olduğunu belirtmişlerdir (11). Zori (2010) et al yönetici hemşirelerde yaptıkları çalışmalarında eleştirel düşünme eğilimi alt boyutları puan ortalamalarını sırasıyla; açık fikirlilik 43.33 \pm 5.29 , analitiklik $45.37 \pm 5.41$, meraklılık 50.50 \pm 5.10 , kendine güven $47.82 \pm 6.00$, doğruyu arama $42.08 \pm 5.19$ ve sistematiklik $44.54 \pm 5.14$ olarak hesaplamışlardır (13). Wangensteen et al (2010) hemşirelerle yaptıkları çalışmalarında eleştirel düşünme eğilimi alt boyutları puan ortalamalarını sıra-

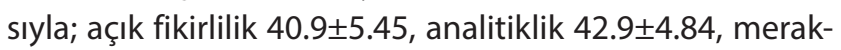
lılık 48.0 \pm 5.67 , kendine güven $41.2 \pm 6.53$, doğruyu arama $39.4 \pm 5.85$ ve sistematiklik $45.5 \pm 6.18$ olarak hesaplamışlardır (14). Çalışmamızda ise hemşirelerin eleştirel düşünme ölçeği alt boyutlarından aldıkları puanlar incelendiğinde; analitik düşünce alt boyutu 46.15 puan, açık fikirlilik alt boyutu 44.13 puan, meraklılık alt boyutu 41.77 puan, kendine güven alt boyutu 30.24 puan, doğru analiz yeteneği alt boyutu 24.74 puan, sistematiklik alt boyutu 23.82 puan olarak hesaplanmıştır. Eleştirel düşünme düzeyinin ortalama puanı ise 210.85 olarak hesaplanmıştır. Bu çalışma ile diğer çalışma sonuçları kıyaslandığında hemşirelerin puan ortalamalarını düşük olduğu görülmüştür. Bunun nedeni; eğitim sistemindeki, çalışma koşullarındaki ve kurum işleyişindeki farklılıklar, beklentiler, iş doyumsuzluğu ve yönetimin eleştirel düşünmeyi destekleyici ve uyarıcı yaklaşımlarının sınırlı olması gibi faktörler olabilir (12).

Eleştirel düşünme becerisinin gelişmesini sağlayan önemli yöntemlerden biri probleme dayalı öğrenmedir (1). Bu çalışmada hemşirelerin büyük çoğunluğunun eleştirel düşünme kavramını iş ortamında öğrendikleri belirlenmiştir (Tablo 3). Bunun nedeni hemşirelik mesleğinin ekip çalışması gerektirmesi, çalışma koşullarının zor olması, yapılan girişimlerin büyük sorumluluklar getirmesi gibi nedenlerle problemlerin daha fazla yaşanması olarak açıklanabilir.

Tablo 3. Hemşirelerin Eleştirel Düşünme Ölçeği alt boyutlarının puan dağılımı

\begin{tabular}{lcccc} 
Alt boyutlar & Ortalama & (SS) & Min & Max \\
\hline Analitik düşünce & 46.15 & 5.53 & 31 & 56 \\
Açık fikirlilik & 44.13 & 9.02 & 30 & 64 \\
Merakllık & 41.77 & 4.72 & 30 & 50 \\
Kendine güven & 30.24 & 5.18 & 14 & 40 \\
Doğru analiz yeteneği & 24.74 & 4.81 & 17 & 37 \\
Sistematik & 23.82 & 2.95 & 18 & 31 \\
Toplam & 210.85 & 32.21 & 140 & 278
\end{tabular}

\section{Sonuç ve öneriler}

Turgut Özal Tıp Merkezi ameliyathanesinde çalışan hemşirelerin eleştirel düşünme eğilimleri ve etkileyen faktörlerin incelenmesi amacıyla tanımlayıcı türde yapılan bu araştırma sonunda şu sonuçlar elde edilmiştir:

Araştırmaya katılan hemşirelerin California Eleştirel Düşünme Eğilim Ölçeğinin puan ortalamasının 210.85, alt ölçek puan ortalamalarının, analitikte $46.15 \pm 5.53$, açık fikirlilikte $44.13 \pm 9.02$, meraklılıkta $41.7 \pm 4.72$, kendine güvende $30.24 \pm 5.18$, doğru analiz yeteneğinde $24.74 \pm 4.81$, sistematiklikte $23.82 \pm 2.95$ olduğu ve hemşirelerin eleştirel düşünme eğilimlerinin düşük düzeyde olduğu bulunmuştur.

Hemşirelerin eleştirel düşünmesini sağlayacak kurumsal politikaların geliştirilmesi, eleştirel düşünme becerilerinin hizmet kalitesine yansımasını ölçen çalışmaların yapılması, hemşirelerin eleştirel düşünmelerini etkileyen faktörleri belirleyen çalışmaların yapılması, bu araştırmanın genellenebilmesi için daha büyük gruplara uygulanması önerilebilir. 


\section{Kaynaklar}

1. Cantürk-Günhan B, Başer N. Probleme Dayalı Öğrenmenin Öğrencilerin Eleştirel Düşünme Becerilerine Etkisi. TEBD 2009;7:451-82.

2. Erkuş B, Bahçecik N. Özel Hastanelerde Çalışan Yönetici Hemşirelerin ve Hemşirelerin Eleştirel Düşünme Düzeyi ve Problem Çözme Becerileri. MÜSBED 2015;1:1-9.

3. Beşoluk Ş, Önder İ. Öğretmen Adaylarının Öğrenme Yaklaşımları, Öğrenme Stilleri ve Eleştirel Düşünme Eğilimlerinin İncelenmesi. Elementary Education Online 201;9:679-93.

4. Arslan ŞF, Ancın V. Sağlık Hizmetleri Meslek Yüksekokulu Öğrencilerinin Eleştirel Düşünme Eğilimlerinin Incelenmesi. Uşak Üniversitesi Sosyal Bilimler Dergisi 2016;9:73-99.

5. Huang Y-C, Chen H-H, Yeh M-L, Chung Y-C. Case Studies Combined With Or Without Concept Maps Improve Critical Thinking In HospitalBased Nurses: A Randomized-Controlled Trial. International Journal of Nursing Studies 2012;49:747-54. [CrossRef]

6. Durmuş İskender $M$, Karadağ A. Hemşirelik Son Sınıf Öğrencilerinin Eleştirel Düşünme Düzeylerinin Belirlenmesi. DEUHFED 2015;8:3-11.

7. Öztürk N, Ulusoy H. Lisans ve Yüksek Lisans Hemşirelik Öğrencilerinin Eleştirel Düşünme Düzeyleri ve Eleştirel Düşünmeyi Etkileyen Faktörler. Maltepe Üniversitesi Hemşirelik Bilim ve Sanatı Dergisi 2008;1:15-25.
8. Kökdemir D (2003)."Belirsizlik Durumlarında Karar Verme ve Problem Çözme" Ankara. Ankara Üniversitesi Sosyal Bilimler Enstitüsü Sosyal Psikoloji Anabilim Dalı, Doktora Tezi.

9. Yuva, E. (2011). "Ankara Üniversitesi Tıp Fakültesi Cebeci Araştırma ve Uygulama Hastanesi Hemşirelerinin Eleştirel Düşünme Eğilim Düzeylerinin Bazı Değişkenler Açııından İncelenmesi" Ankara. Atıım Üniversitesi Sosyal Bilimler Enstitüsü Sağlık Kurumları İşletmeciliği Anabilim Dalı, Yüksek Lisans Tezi.

10. Gürol Arslan G, Demir Y, Eşer I, Khorshıd L. Hemşirelerde Eleştirel Düşünme Eğilimini Etkileyen Etmenlerin İncelenmesi. Atatürk Üniversitesi Hemşirelik Yüksekokulu Dergisi, 2009;12:72-80.

11. Karadağ $M$, Alparslan Ö, Pekin İşeri Ö. Ebelik ve Hemşirelik Öğrencilerinin Eleştirel Düşünme Eğilimleri ve Öğrenme Stilleri. Cukurova Med J 2018;43:13-21. [CrossRef]

12. Eşer İ, Khorshıd L, Demir Y. Yoğun Bakım Hemşirelerinde Eleştirel Düşünme Eğilimi ve Etkileyen Faktörlerin İncelenmesi. C.Ü. Hemşirelik Yüksekokulu Dergisi 2007;11:13-22.

13. Zori S, Nosek LJ, Musil CM. Critical Thinking of Nurse Managers Related to Staff RNs' Perceptions of the Practice Environment. Journal of Nursing Scholarship 2010;42:305-13. [CrossRef]

14. Wangensteen S, Johansson IS, Björkström ME, Nordström G. Critical Thinking Dispositions Among Newly Graduated Nurses. J Adv Nurs. 2010;66:2170-81. [CrossRef] 